\title{
DEL OYENTE RECEPTOR AL OYENTE COMBATIENTE ${ }^{1}$
}

\author{
Xose A. Padilla García \\ Universitat d'Alacant. Grupo Val.Es.Co. \\ Xose.Padilla@ua.es
}

\begin{abstract}
Resumen
This paper offers a comparative analysis of the components of Shannon and Weaver's theory of information (1949) transmitter/receiver and the pragmatical concepts speaker/hearer (cfr. Yule, 1996). We will defend that, in order to undertands how human communication happens, both the role of the hearer and non-verbal emissions must be revised. We will work on a corpus of colloquial conversations (cfr. Briz y Grupo Val.Es.Co., 2002) and we will analyse all the occasions in which speaker and listener comunicate without words. The use of a conversational corpus reveals that trasmition and reception of information are permanent activities not equivalent to the act of intentional communication.
\end{abstract}

\section{Introducción}

El trabajo que aquí presentamos relaciona las figuras de la comunicación emisor y receptor con los conceptos de la pragmática ${ }^{2}$ hablante y oyente. El objeto de nuestra investigación es partir de situaciones comunicativas reales y aprovechar la ayuda que pueda aportar a la descripción de la comunicación humana el estudio de la conversación y de sus diferentes unidades.

Retomando algunas ideas señaladas ya en otras investigaciones (véase Goffman, 1979, 81; Ducrot, 1984; Sperber y Wilson, 1986; Kerbrat-Orecchioni, 1986; Levinson, 1989; Gallardo, 1993, 96), tenemos dos propósitos principales: (a) reivindicar un papel activo para la figura del oyente y (b) redefinir el concepto emisor como algo más que la persona que produce sonidos.

Hemos tomado como punto de partida del análisis el corpus de conversaciones coloquiales del Grupo Val.Es.Co. ${ }^{3}$ y nos hemos apoyado en términos generales en las últimas investigaciones del grupo sobre la descripción de las unidades conversacionales ${ }^{4}$.

\footnotetext{
1 El presente trabajo ha contado para su realización con la subvención derivada de los proyectos de investigación HUM2004-01453/FILO "Nuevas Aportaciones al Diccionario de Partículas del Español" y HUM2004-01318/ FILO "Análisis pragmático de la ironía verbal. Tipología y aplicaciones a la enseñanza del español como lengua extranjera", subvencionados ambos por el Ministerio de Ciencia y Tecnología.

2 Aunque hoy en día no existe una terminología consensuada, sí podemos decir que los conceptos emisor y receptor pertenecen (al menos en sus origenes) a Shannon y Weaver (1949) y que los conceptos hablante y oyente pertenecen a la disciplina lingüística en general, $y$, muy especialmente, a la pragmática como encargada del análisis de la lengua en uso. Encontramos definiciones de estos términos en Yule (1996), Escandell (1996), etc.

3 Véase Briz y Grupo Val.Es.Co. (2002).

4 Véase Briz y Grupo Val.Es.Co. (2003) y Hidalgo y Padilla (en prensa).
} 


\section{La teoría de la información}

Las primeras reflexiones sobre los elementos que intervienen en los intercambios de información se deben a un ingeniero de telecomunicaciones y a un sociólogo. Shannon (1948) y Weaver (1949) $)^{5}$ fueron pioneros en explicar el modo en que funcionan los intercambios de información, hablando de siete elementos: la fuente, el emisor, el mensaje, el receptor, el destino, el ruido y el canal, esquematizando así algo que podríamos entender como la secuencia informativa básica. ${ }^{6} \mathrm{El}$ origen de este esquema era el análisis de sistemas de información mecánicos; y su objetivo, la explicación matemática de la comunicación telefónica. Para hacernos una idea elemental de lo que el esquema de Shannon y Weaver representa podemos pensar en una antena de radio y en un aparato receptor. La antena transmite una señal, el aparato receptor la recibe, y, entre uno y otro, se encuentra el mensaje (una secuencia de información revestida de contenido semántico).

El esquema de Shannon y Weaver fue aplicado por primera vez a cuestiones lingüísticas por Jakobson (1950) que sustituye las figuras mecánicas por humanos, y habla de un destinador (un emisor) y un destinatario (un receptor). Desde la adaptación de Jakobson, los lingüistas han criticado la simplicidad de este primer esquema, aduciendo que la comunicación humana es un proceso mucho más rico y complejo. Sin embargo, la mayor parte de las teorías siguen contemplando el proceso como una secuencia estática, y, lo que es más importante, como un sistema fonocéntrico que da un papel preponderante al emisor?

En las propuestas de Ducrot (1984), Goffman (1979, 81), Levinson (1989), o incluso Sperber y Wilson (1986), el emisor elige un destinatario entre todos receptores posibles y los sonidos son los únicos elementos comunicativamente relevantes. Si analizamos la comunicación tomando como punto de partida una conversación coloquial, nos daremos cuenta de que conversar es emitir sonidos, desde luego, pero también emitir gestos, movimientos, risas o simples miradas, $y$, lo que es más importante, conversar es reclamar, como veremos más tarde, un papel fundamental para aquel que atiende y escucha ${ }^{8}$.

5 La fórmula de Shannon (1948), que ha pasado a la historia de la ciencia como una de las grandes aportaciones del siglo XX, sorprendió a Weaver (1949) de tal manera que decidió que su aplicabilidad superaba el restringido ámbito de la comunicación telefónica. Los comentarios de Weaver dieron a conocer a Shannon a la comunidad científica general, y al final ambos trabajos se publicaron como un único libro que tomó el nombre del artículo de Shannon y pasó a conocerse en el ámbito científico como la teoría de la información.

6 Una de las aportación más interesantes de Shannon (1948) es que la entropía (el ruido) es un elemento fundamental en los intercambios de información, ya que existe un cierto grado de incertidumbre de que el mensaje llegue completo.

7 En realidad, todas estas propuestas, a pesar de su heterogeneidad, son herederas de las corrientes filosóficas del siglo XX (véase Bajtin, 1977), encaminadas a la destrucción de la unicidad del sujeto, y de la necesidad lingüística, rara vez superada, de no romper el cordón umbilical que conecta la descripción lingüística con la forma sonora. En este sentido, Ascombre y Ducrot (1983) hablan desde la teoría polifónica de locutor, emunciador, alocutario, etc. Levinson (1989), por su parte, tomando como punto de partida sus investigaciones sobre la lengua chinook, distingue una fiente (el jefe), distinta del hablante o portavoz (el hechicero), y un objetivo (los espíritus), distinto a su vez de los oyentes o testigos (los otros miembros de la tribu).

8 Esto es fundamental en cuestiones pragmáticas como la ironía, en las que el hablante no sólo cuenta con el oyente para interpretar el enunciado sino también para construirlo (véase Padilla, en prensa 1). 


\section{La esfera natural}

Uno de los primeros pasos para describir cómo nos comunicamos en una conversación coloquial es señalar la existencia de dos esferas diferentes: (a) la esfera natural y (b) la esfera social.

Para explicar lo que es la esfera natural puede ser interesante comparar el comportamiento comunicativo de los humanos y de las máquinas, atendiendo, principalmente, a aquel que reproducen las computadoras.

Si examinamos las investigaciones más recientes en inteligencia artificial, nos encontraremos con máquinas que imitan todavía diálogos extremadamente sencillos'. Un usuario, por ejemplo, pide un billete de tren por teléfono y la máquina expide un ticket:

(1)

Máquina: ¿destino/ por favor?

Usuario: Valencia

Máquina: gracias/ ha dicho usted Valencia/ ¿billete de ida y vuelta o sencillo?

Usuario: sencillo

Máquina: gracias/ ha dicho usted sencillo/ recoja su ticket/ por favor

La computadora requiere que todas las variables se acomoden a lo programado, $y$, aún así, en muchas ocasiones, la comunicación no tiene éxito ${ }^{10}$.

Las máquinas expendedoras de billetes y otras máquinas similares ${ }^{11}$, que copian diálogos formados por pares adyacentes, requieren una capacidad de reacción escasa. Las preguntas y respuestas son tan sencillas que las confirmaciones fáticas no son necesarias.

Los seres humanos somos, evidentemente, muy distintos de las máquinas, pero, si nos ceñimos a lo estrictamente comunicativo, la primera diferencia que encontramos es que nosotros, mientras hablamos, no dejamos de emitir y recibir información. Las comunicaciones mecánicas que plantearon Shannon y Weaver (1949) presuponen la independencia absoluta de la emisión y la recepción. Los humanos, a diferencia de lo anterior, somos emisores y receptores permanentes, algo que podríamos bautizar, si se nos permite el término, como emirrecs ${ }^{12}$.

\subsection{Qué es emisión permanente}

Igual que la recepción es una actividad constante, en nuestro trabajo propondremos que la emisión humana también lo es ${ }^{13}$. Para apoyar esta afirmación, consideraremos que los

9 Para obtener más información, pueden consultarse los trabajos del grupo BASURTE de la Universitat Politècnica de València.

10 La opinión de los expertos en esta disciplina es que no se producirán grandes avances en un plazo corto de tiempo, pues consideran que, a pesar de los logros conseguidos en los últimos cincuenta años, los nuevos frutos llegarán muy despacio. Véase Pla et al., (2001); Segarra et al., (2002); Sanchis et al., (2002).

11 Por ejemplo el Robocom, un "juguete mecánico" de origen coreano que permite sencillos diálogos para aprender inglés.

12 Cuando hablamos de emirrecs ampliamos el concepto retroalimentación (véase Gallardo, 1996). La emisión es igual de constante que la recepción.

13 Nadie, a no ser que nos tapemos los ojos, los oídos o la nariz, negaría que estamos recibiendo permanentemente imágenes, sonidos u olores. Sin embargo, no parece tan fácil admitir que la emisión sea un proceso continuo, y la razón que justifica esta actitud negativa es considerar que la emisión, como han hecho la mayoría de los investigadores, es una actividad exclusivamente sonora. 
estímulos comunicativos son un conjunto heterogéneo en el que, además de los sonidos, debemos incluir cientos de mensajes que los participantes conversacionales comunican con sus gestos, con sus ojos o con su olor. Esos miles de estímulos que producimos y recibimos a lo largo del día, y que completan aquello que estamos diciendo, nos diferencian de las máquinas, y nos convierten en emisores y receptores permanentes (emirrecs).

\section{La esfera social}

Hasta el momento, hemos intentado describir la comunicación centrándonos en el hecho individual ${ }^{14}$. Ahora bien, en la comunicación conversacional, además del hecho individual, hay un hecho social, por esta razón, hablamos de dos esferas distintas.

El acto de emitir y recibir información y el acto de comunicar son procesos diferentes. Una persona sentada en el autobús, en el tren, o en cualquier otra parte, produce y recibe mensajes continuamente, sin embargo, a pesar de haber sido emitidos y posteriormente recibidos, no todos estos mensajes tienen la intención manifiesta de comunicar. Comunicar es un hecho intrínsecamente social, por lo tanto, no podemos confundir trasmitir información con el acto intencional de comunicar ${ }^{15}$. Así, detrás de la capacidad emisora-receptora natural que hemos mencionado antes, tenemos que contar además con la confluencia de dos factores: (a) la existencia de al menos dos personas y (b) el deseo expreso de comunicar. Este deseo expreso de comunicar ha sido definido desde la pragmática como intención pragmática o simplemente intención ${ }^{16}$. En palabras de Leech (1983), hay intención en aquellas emisiones que tienen un objetivo o una meta, es decir, en aquellas emisiones que pretenden actuar sobre el estado de cosas preexistente con el propósito de modificarlo.

En una conversación coloquial, se distinguen perfectamente las dos esferas (la natural y la social), por lo tanto, cuando dos individuos definidos como emisores y receptores simultáneos deciden conversar, deben adquirir un papel social en el que combinan la transmisión de información y la intención de comunicar.

\subsection{El papel de las unidades conversacionales}

Para definir el papel social de un participante conversacional, es necesario analizar brevemente la función que representan en todo el proceso las unidades conversacionales (véase Briz y Grupo Val.Es.Co., 2003).

Cuando intentamos definir una conversación, pensamos de forma inmediata en turnos que se alternan y suceden. Dos personas conversan porque una habla y la otra escucha, pero, sobre todo, porque los papeles comunicativos se intercambian.

Es divertido observar las conversaciones entre niños muy pequeños. Vistas desde fuera se parecen mucho a las de los adultos (hay dos personas que emiten y reciben mensajes), pero, si las analizamos más de cerca, observaremos que son muy distintas de lo que nosotros

14 Ser emisor y receptor es una capacidad, como decimos, permanente, pero atribuible de manera particular todos los miembros de una comunidad lingüística determinada.

15 Un bostezo, por ejemplo, mientras viajo en autobús, indica simple aburrimiento; un bostezo, mientras converso con alguien, pude significar mucho más que aburrimiento.

16 Encontramos una revisión de las diferentes definiciones del concepto intención en Escandell (1996:34). 
entendemos realmente por conversar. Las conversaciones infantiles son fundamentalmente monólogos sucesivos ${ }^{17}$, es decir, intervenciones individuales en las que el interlocutor apenas cuenta. Los niños en el desarrollo de la competencia comunicativa ${ }^{18}$ tienen que aprender que conversar es también atender a lo que dice el otro, y que en este proceso los dos interlocutores obtienen diversos beneficios ${ }^{19}$.

Podríamos afirmar, por lo tanto, que los turnos son el eje central del proceso de conversar. Briz (2000) define el turno como: “(...) un hueco o lugar de habla rellenado por emisiones informativas que son reconocidas por los interlocutores mediante su atención manifiesta y simultánea, la unidad que hace que la conversación progrese dentro de un orden".

Si partimos de la definición anterior, debemos considerar dos aspectos en el concepto turno: (a) su carácter estructural (toda conversación es una sucesión de turnos ${ }^{20}$ ) y (b) su carácter social (emisiones informativas reconocidas por los interlocutores).

Si volvemos nuevamente al lenguaje infantil, podríamos decir que es posible que los niños aprendan antes su carácter estructural que su carácter social. Es decir, los niños, en una primera fase, juegan a conversar, $y$, en una segunda, revisten este juego de una función social.

Buena parte de las investigaciones ${ }^{21}$ sobre el funcionamiento de la conversación han incidido especialmente en el aspecto estructural. El Grupo Val.Es.Co., como muestra la definición anterior, tiene en cuenta los dos aspectos: el estructural y el social.

\subsection{Turno e intervención}

Una conversación es, pues, una sucesión de turnos, sin embargo, no todas las emisiones que se producen en la misma pueden ser definidas como tales. Para verlo de manera más clara podemos analizar el siguiente diálogo entre dos informáticos:

(2)

$1 \mathrm{~A} 1^{22}$ :

$\S$ yo recuerdo un modelo de cola de una máquina de memoria virtual $\uparrow$ ((había un)) disco $\uparrow$ de memoria $\uparrow$ y una serie de peticiones/ pues eso/ entras en ((fase)) y sales/ adiós sistema

2B1: o sea pero ¿llegáis a esa situación? o sea [por ejemplo ¿en qué?=]

2A2:

[nosotros llegamos sí sí]

$2 \mathrm{~B} 2:=$ ¿en qué- en qué medida se nota para un usuario de Teseó corto en tiempo [e respuesta?]

3A3:

[nosotros] hemos

llegado a estar/ veinte y treinta segundos para pasar de una pantalla a otra/ cosa

17 Véase Padilla (1996).

18 Véase Hymes (1971).

19 Véase Baixauli (1997) y Padilla y Baixauli (2000).

20 Sin turnos no hay diálogo.

21 Es lo que sucede, por ejemplo, en el análisis que llevan a cabo los etnometodólogos (véase Sacks et al. 1974; Sacks, Schegloff y Jefferson, 1977; Sacks, 1986; etc.)

22 Las cifras a izquierda y derecha de la inicial del participante indican los turnos e intervenciones respectivamente. Asi, por ejemplo, la emisión $2 \mathrm{~B} 1$ debe leerse como el segundo turno de la conversación y la primera intervención del participante $\mathrm{B} ; 5 \mathrm{~A} 4$, como el quinto turno de la conversación y la cuarta intervención del participante A; etc. 


\section{que normalmente el- el sistema te responde de modo instantáneo// hemos llegado a experimentar $\S$ \\ 4B3: \\ 5A4: nada/ menos de un segundoß \\ $\S$ instantáneo es un segundo ¿no?}

$$
[\text { XP.48.A.1 }]^{23}
$$

Las dos emisiones del participante A marcadas en negrita en el fragmento (2A2 y $3 \mathrm{~A} 3$ ) son muy distintas entre sí. La primera es una interrupción, una emisión de A dentro de la emisión de B; la segunda es un turno propiamente dicho, pues encuentra su complemento en la emisión siguiente del participante B (4B3). La primera emisión se pierde en el flujo de palabras, significa poco realmente para el avance de la conversación; la segunda, sin embargo, sí entra a formar parte del diálogo y obedece a la obligatoria alternancia de turnos.

El Grupo Val.Es.Co. ha decidido acuñar dos términos distintos para estos dos tipos de emisiones. El primero, la emisión que no es atendida por el otro participante, recibe el nombre de intervención; el segundo, la que sí es atendida, recibe el nombre de turno ${ }^{24}$.

La distinción entre turnos e intervenciones permite diferenciar, por otra parte, dos papeles socio-conversacionales: el hablante y el oyente. Estos dos papeles son independientes de la caracterización natural (emisor-receptor), atribuible, como hemos dicho, al cualquier persona por el mero hecho de serlo. Si un emirrec posee el turno de habla (como sucedía con el participante $\mathrm{A}$ en la emisión 3A3), es definido como hablante; si un emirrec no posee el turno de habla (como sucedía con el participante A en la emisión 2A2) es definido como oyente.

\section{Hablante (emirrec) $\longrightarrow$ (emirrec) Oyente COMUNICACIÓN}

\section{Gráfico 1}

Como la caracterización natural y la caracterización social son, como hemos dicho, hechos autónomos, no es incompatible que un individuo sea marcado a la vez como oyente y como emisor (como sucede en la intervención 2A2). La descripción natural es permanente, la descripción social empieza y acaba en el acto mismo de comunicar, en la alternancia de turnos.

\section{Intercambio de información vs. comunicación}

La división entre emisiones atendidas (turnos) y emisiones no atendidas (intervenciones), nos permite seguir profundizando en las diferencias existentes entre los términos comunicar e intercambiar información. Para ello relacionaremos las esferas natural y social con lo que Leech (1983) definió como intención pragmática.

Representaremos esta relación a través del siguiente gráfico:

23 Todos los ejemplos que pertenecen al corpus Val.Es.Co. (2002) llevan la clave que nos informa de la conversación de la que fueron extraídos.

24 En realidad, esta división permite diferenciar dos aspectos distintos de la conversación. Una dimensión estructural, es decir, una sucesión de intervenciones; y una dimensión social, es decir, una sucesión de turnos. Una conversación estaría formada por intervenciones sucesivas, pero sólo una parte de ellas serían turnos.

Sería algo así como el armazón de la conversación, su esqueleto. Véase Briz y Grupo Val.Es.Co. (2002). 
Intervención<smiles>CC</smiles>

Emirrec - mensaje - Emirrec

(componentes informativos)

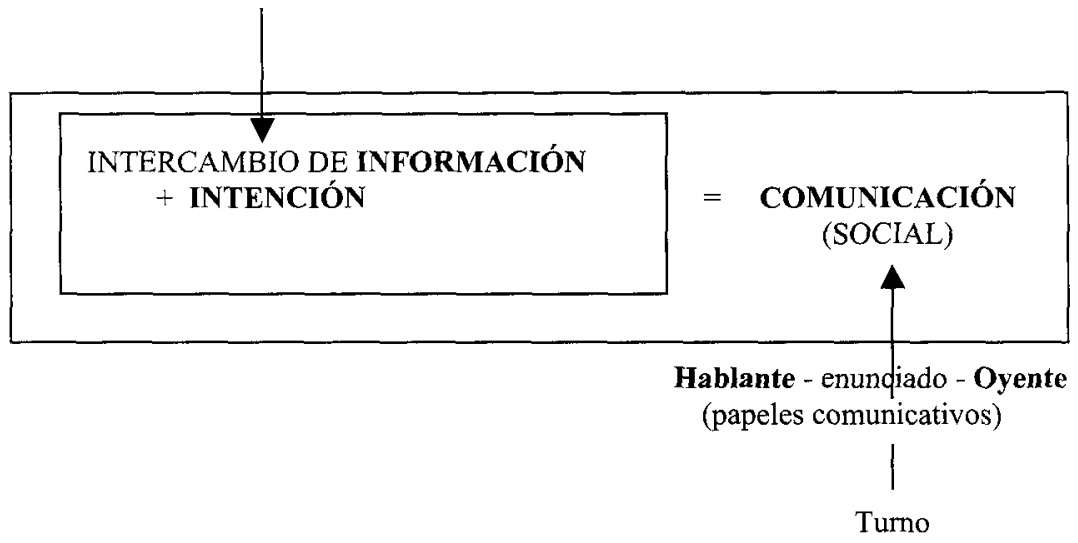

Gráfico 2

Partiendo siempre de lo que sucede en una conversación coloquial, la ecuación que se senala en el gráfico permite separar de forma más clara los términos intercambiar información y comunicar. Un intercambio de información es un proceso constante en el que adquieren un protagonismo principal los componentes de la esfera natural (los emirrecs). Un proceso de comunicación, como se señala en el gráfico, es un intercambio de información al que se suma la intención pragmática; este intercambio se convierte en un hecho social y, en este caso, adquieren protagonismo los componentes de la segunda esfera (hablante y oyente) ${ }^{25}$.

\section{Reivindicando un oyente activo}

Esta diferenciación en dos esferas distintas permite, en nuestra opinión, una visión más clara de lo que es realmente la comunicación humana, pero, además de esto, ayuda, a reivindicar, como veremos a continuación, el papel del oyente.

Cualquier conversación que analicemos nos autoriza a afirmar que la posesión del turno es un valor anhelado por todos los participantes. Podemos comprobarlo examinando el siguiente fragmento ${ }^{26}$ :

25 Desde un punto de vista conversacional, en el primer caso, hablariamos de emisión de intervenciones; y en el segundo caso, de intervenciones que pasan a ser reconocidas como turnos (emisiones sociales).

$26 \mathrm{C}$ es la madre, $\mathrm{A}$ es el hijo y $\mathrm{B}$ es el padre. El padre y el hijo trabajan juntos como albañiles. 
(3)

$1 \mathrm{C} 1$ :

$\S$ imaree $!^{27} \S$

2A1: $\S$ este- este ${ }^{28}$ se mantiene de piee/// este se mantiene de piee ;telaa! $/ /^{29}$ tiene buena hoja/ ¡hombree!/// (es)te tiene buena hoja

$3 \mathrm{C} 2$ : cuando estés bueno y eso/ que bajes y te hará un análisis o algo ${ }^{30}$ para $[$ mirar $\rightarrow$ ]

3A2: [vale] setecientas o seiscientas pelaas§

4C3:

$\S$ yo digo entre mí [si l'hace $\uparrow]$

4B1:

[sete- cientas] pelas

vale $\downarrow$ [hacerlo]

4C3: $\quad[¿ E H ?]$ yo le digo si l'hace un análisis que sea el análisis d'alcohol $\downarrow$ más vale que no se l'hagall/ (( ))

5A3: ¡menuda ((faena)) hay si tengo que ir allí $\downarrow$ yo!

[RV.114.A.1]

En el ejemplo anterior, todos los participantes luchan por mantener o arrebatar el turno de habla. La participante $\mathrm{C}$, la más activa, retoma el turno en $4 \mathrm{C} 3^{31} \mathrm{y}$, a pesar de las intervenciones $3 \mathrm{~A} 2$ y $4 \mathrm{~B} 1$ de los otros dos participantes, no lo abandona hasta 5A3. Ni siquiera un interrogativo $¿ \mathrm{EH}$ ?, solapado con la intervención del participante $\mathrm{B}$, sirve a $\mathrm{C}$ para atender a lo que los otros participantes dicen.

Muchas conversaciones coloquiales podrían definirse como verdaderas "batallas" en las que los participantes, lo consigan o no, luchan encarecidamente por arrebatar el turno a su oponente.

En el ejemplo (4), la participante B (una madre) está expresando una opinión negativa sobre la capacidad de conducción de un amigo de su hija (participante A):

(4)

1B1: PUES/ CON JOSE no subas AHÍ $\rightarrow$ con esas curvas al desierto $\uparrow$ ¿eh?§

2A1:

ES EL QUE MEJOR CONDUCE oo Víctor// igual lo coge Víctor\$

3B2:

$\S$ PUES SI JOSE

[no está EXPERTO $\uparrow$ MONICA]

$\S$ pero Jose

3A2: $\quad$ [iyo ((son de los)) que más me] fío!

3B2: pero que no está EXPERTO $\downarrow$ JOSE§

4A3:

4B3:

$\S$ peroo[va con mucha más precaución=]

[pero escúchame ((pero escucha))]

4A3: = IRÁ/ pero si IRÁ a diez por hora con lo miedoso que es él

5B4: las curvas al desierto $\downarrow$ ojo $¿$ eh?// jaayy/madre mía! $!^{32}$

[V.117.A.1]

27 Valenciano-catalán, "madre".

28 Se refiere al metro.

29 Reducción de la expresión de sorpresa o asombro "itela marinera!".

30 C retoma el tema médico.

31 En realidad, entre las intervenciones $3 \mathrm{~A} 2$ y $4 \mathrm{C} 3$, se produce un lugar de transición pertinente (LTP), es decir, un punto de la conversación que normalmente es aprovechado para ceder el turno y cambiar de hablante. Paradójicamente este LTP es aprovechado por el mismo hablante C para continuar hablando. Véase Geluykens (1992) o Hidalgo (1997).

32 Esta interjección se escucha desde lejos porque B se ha ido a la cocina. 
Las dos participantes emiten opiniones enfrentadas, como muestran los continuos solapamientos y los conectores argumentativamente antiorientados (los peros), sin embargo, ninguna de las dos presta atención al resto de las intervenciones. De hecho, la participante $\mathrm{B}$ (la madre) lo pone claramente de manifiesto en la intervención 4B3, rogando dos veces la atención de su hija: pero escúchame, pero escucha.

Atendiendo a lo anterior, no nos resultará extraño admitir que la conversación coloquial haya sido definida como una actividad egocéntrica (véase Briz, 1998), pues parece como si, en ocasiones, cuando conversamos, regresáramos a los monólogos excluyentes de la etapa infantil. Lo que dice el otro casi no importa ${ }^{33}$.

Como la condición de hablante y oyente y la condición de emisor y receptor pertenecen, como hemos dicho, a esferas distintas, podemos afirmar que el hablante (el que posee el turno) no es el único participante conversacional activo o emisor. En los casos en los que el oyente (véanse ejemplos 3 y 4) interviene estratégicamente para intentar robar el turno de habla, estamos también ante un oyente claramente emisor. Dicho de otra manera, un oyente combatiente.

\section{Otros tipos de oyente-emirrec}

Además de combatir, el oyente puede, o mejor dicho, debe ratificar la condición social de los participantes conversacionales. De hecho, a pesar de su capacidad combativa, ésta es teóricamente su actividad habitual. Esto se ve de forma más clara con un ejemplo. Imaginemos que una persona entra en una sala y comienza a hablar, por ejemplo, un profesor en una aula llena de alumnos parlanchines. El profesor comienza la lección y ningún alumno le atiende; pues bien, sólo cuando los presentes le manifiestan su atención, cuando atienden a sus palabras, se convierte el profesor en hablante. Hasta entonces sus intervenciones no son turnos.

Como la actividad emisora es constante, el hablante recibirá continuos estímulos del oyente, en este caso, la mirada de los alumnos y su silencio. Así, asumiendo la definición de turno que mencionamos anteriormente ${ }^{34}$, podemos decir que para que exista diálogo, para que el hablante realmente lo sea, el oyente debe dejar constancia de su atención manifiesta y simultánea. Esto significa que el elemento decisivo en la definición del turno, y, por consiguiente, en la asignación de los papeles conversacionales, no es el hablante sino el oyente. El oyente determina la repartición de los turnos; el hablante es, pues, a diferencia de lo que proponía Goffman $(1979,81)$, el elemento ratificado ${ }^{35}$.

\section{Estímulos fáticos sonoros}

La actividad emisora-ratificadora del oyente puede ser de dos tipos: (a) verbal (sonidos) y (b) no verbal (miradas, gestos, etc.). El ejemplo prototípico de oyente con actividad emisora verbal lo proporcionan las conversaciones telefónicas. En las conversaciones telefónicas, la actividad emisora del oyente, aunque sea de forma muy breve, tiene siempre 
que verbalizarse ${ }^{36}$. La experiencia diaria nos permite corroborar que existen diversos tipos de interlocutores telefónicos, y que unos son más o menos fáticos que otros, pero hasta los interlocutores menos colaborativos necesitan producir de vez en cuando emisiones confirmativas del tipo $\mathrm{mm}$, sí, etc. para ratificar el papel del hablante al otro lado del teléfono.

Veamos el siguiente ejemplo:

1A1: pues como te iba diciendo $\uparrow$ la capulla de Marta vino y me dijo-¿me estás oyendo? ¿ANA?

2B1: sí, sigue

$3 \mathrm{~A} 2:$ pues $[\mathrm{eso}]=$

3B2: $\quad[\mathrm{mm}]$

3A2: =que mi Borja tonteaba con Carla ¿tú te crees?

Los hablantes solicitan, y en muchos casos exigen, su confirmación como poseedores del turno, y se enfadan, como le ocurre a la hablante A, si el oyente olvida dicha confirmación.

En las conversaciones coloquiales ocurre algo parecido a las conversaciones telefónicas, $\mathrm{y}$, a pesar de que el canal permite, como veremos después, confirmaciones con estímulos diferentes a los sonoros, el oyente suele utilizar también ratificaciones orales similares a las señaladas para el teléfono.

Examinemos el ejemplo (6):

(6)

1S1: a ver/ súbete a la mesa y da así una vueltecita ${ }^{37}$

2A1: sí hombre $\downarrow$ pase de modelo(s) ahora $\downarrow$ a ehtah alturah ya/ [icómo me voy a (( ))] $3 \mathrm{~S} 2$ [tú imagínate que esto $\uparrow] /$ esta mesa $\uparrow] /$ como es largaa $\uparrow \S$

$4 \mathrm{~A} 2:$

5S3:

6A3:

7S4: yy-

[AP.80.A.1]

\section{$\S \mathbf{m m} \S$}

$\S$ imagínate que es la Pasarela Cibeles ${ }^{38} \S$

$\S \mathbf{m m}$

En ejemplo anterior, el participante $S$ tiene el papel social de hablante, y la participante A, el papel social de oyente. El hablante (S) dirige aparentemente la conversación (da órdenes, recrea una situación, etc.), pero el oyente (A) es realmente la persona que legitima el reparto de turnos, pues confirma al hablante en su papel con los $m m$ fáticos de las emisiones $4 \mathrm{~A} 2$ y $6 \mathrm{~A} 3$.

36 El teléfono es normalmente un trasmisor de sonidos, aunque hoy podemos enviar imágenes, su uso no está todavía generalizado. De momento, es imposible trasmitir otro tipo de estímulos, pero los investigadores prometen que pronto se trasmitirán los olores.

37 Entre tisas.

38 Pasarela de moda de Madrid. 


\section{Estímulos fáticos no sonoros}

Pero, además de los ejemplos en los que el hablante es confirmado verbalmente, la conversación coloquial proporciona otros muchos en los que el oyente pone en funcionamiento una actividad emisora fática diferente de los sonidos o de las palabras.

Todos los estímulos que veremos a continuación (las miradas, los gestos, la presencia física, o las risas) confirman que la actividad emisora de los dos participantes es constante, entendiendo emitir, como dijimos en el apartado 3, como algo más que producir sonidos.

En los siguientes párrafos, examinaremos una serie de casos en los que las ratificaciones del oyente o bien no son estímulos orales o bien son diferentes de las palabras.

\subsection{Las miradas}

Parece obvio que la mirada es el principal elemento de contacto en cualquier conversación coloquial. Hablante y oyente se miran continuamente. El contacto visual ratifica al hablante en su papel ${ }^{39}$, pero, además de esto, las miradas comunican muchas otras cosas ${ }^{40}$. El hablante $\mathrm{D}$, haciendo gala de una cierta ironía, lo verbaliza de forma muy clara al final del ejemplo (7):

(7)

A: no digáis PALABROTAS

D: si son toas unas putas/ hombre

A: no/ todas noß

D:

A: mi madre no $\S$ ¿no?

D: clar- HOMBRE $\downarrow$ exceptuando (RISAS) a nuestras madres/// iayy!/// y todos los cal$\operatorname{vos} \uparrow^{41}$ también $\downarrow$ son unos cabrones

C: [(RISAS)]

A: [(RISAS)]

B: hombre $\downarrow$ en eso ya empezamos aa

A: a disentir un poco§

D: $\S$ yo no

B: siempre tú has estao de acuerdo $\downarrow$ en ese tema/// ¿y tú Raúl $\uparrow$ opinas que los calvos son cabrones $\uparrow$ o no?

C: hombre $\downarrow$ he conocido pocos

D: (RISAS) ¡qué cabrón! y te mira ${ }^{42}$ [(RISAS)]

[H.38.A.1]

39 Evidentemente, en esta cuestión hay diferencias culturales. En este sentido, Suzuki (1978) hace una comparación muy interesante entre japoneses y occidentales.

40 Quizás otro de los gestos escasamente estudiados es la sonrisa. La sonrisa acompaña a la mirada y en muchas ocasiones la complementa. En algunas culturas, la falta de sonrisa puede indicar falta de interés por el discurso del hablante (véase Suzuki, 1978). En español, la sonrisa también tiene un valor fático, pero posee una connotación más maliciosa (irónica) que fática. Si alguien sonríe mientras hablamos, pensamos que detrás de la sonrisa hay una burla (véase Padilla en prensa 1).

41 Se alude con el término "calvo" al novio de la joven mencionada anteriormente.

42 En ese momento $C$ mira a $A$. 
El amor, el odio, el humor ${ }^{43}$ son elementos comunicables a través de los ojos que llegan muchas veces más allá de las palabras. Pero, como decimos, el valor de la mirada no acaba aquí. Además de complementar a los sonidos, las miradas pueden adquirir también valor informativo pleno, equivaliendo, consecuentemente, a verdaderos turnos, repletos de sustancia informativa:

(8)

1A1: ¿cómo ha ido el examen?

2B1: (mirada)

3A2: vale/ no digas más

En el ejemplo (8), la mirada del hablante B contesta la pregunta de A, y tiene su réplica en el turno $3 \mathrm{~A} 2$, por lo tanto, adquiere un valor informativo similar al de cualquier turno oral.

\subsection{Los gestos}

Los gestos que emitimos cuando conversamos son de muy diversa índole (véase Bravo, 2000), pero el gesto más característico para mantener el contacto, al menos en español, es un ligero movimiento de cabeza:

(9)

A: no sé por ahí fuera/ pero aquíi entro^ (( )) (14") ¿así que Castellón está lleno de gente $\uparrow$ ?

B: $\mathbf{m m}$

[V.117.A.1]

Cuando el oyente emite un $\mathrm{mm}$ suele mover la cabeza de arriba abajo en señal de atención. En ocasiones, el movimiento y el $\mathrm{mm}$ se solapan, en otras, como ocurría con la mirada, un solo movimiento basta, como muestra la nota a pie de página de la emisión 4B1:

1C1: es verdad ¡cómo nos reíamos!

2A1: lo que me ref yo $\uparrow$ fue cuando un botella de champán $\uparrow$ le apunté al ojo asî $\uparrow^{44}$

3C2: (RISAS)§

4B1: $\quad \S$ ¿y le diste $\uparrow$ nano $^{45} ?$ ¡no jodas $\downarrow$ tío!

5C3:

él y él estaba de espaldas

$\S$ ibamos $\uparrow$ y estábamos donde estaba

6A2: estábamos ciegos $\downarrow$ completamente

7B2: [(RISAS)]

[H.38.A.1]

43 La nota del transcriptor nos dice que en esos momentos $\mathrm{C}$ mira a $\mathrm{A}$.

44 Entre risas.

45 Movimiento afirmativo con la cabeza, de $\mathrm{A}$. 
En realidad, en la mayor parte de los casos, las emisiones no verbales son el elemento comunicativo realmente importante, pues muchas veces el $\mathrm{mm}$ parece casi una verbalización o efecto de dicho movimiento:

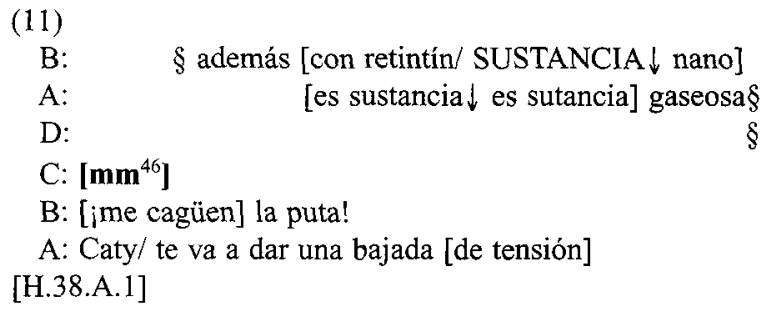

\subsection{La presencia física}

En ocasiones la presencia física equivale también a una emisión y, por consiguiente, a una forma diferente de contacto. La entrada en escena de un personaje ajeno a la conversación, por ejemplo, puede suponer información equivalente en importancia a la de una emisión verbal con valor de turno. El ejemplo (12) sirve como botón de muestra de lo que queremos decir:

1D1: juy!

2A1: hola Mercedes $\S$

3D2: $\quad \S$ ise puede?

4A2: sí sí/ pasa pasa

5D3: ¿qué pasa?

6A3: no/ nada/ charrábamos/y eso

7D4: ¿me voy o me quedo? ¿qué hago? (RISAS)

8A4: no/ no te preocupes

$9 \mathrm{Cl}$ : [bueno ¿qué?]

9A5: [y eso] no sé /// (TOSES)

9C1: lo puede saber ¿no?

10A6: síi/ claro// total $\uparrow$

11D5: bueno $\downarrow$ pues contarme [porque estoy pez] $]^{47}$

12A7: que -¿dón- dónde está Blanca?

[no es-] $]^{48} / /$ no es ningún secreto de estado// que no lo se- $/$

[ML.84.A.]

La entrada inesperada de D violenta la conversación que mantenían A y C, y su inclusión en el diálogo requiere una serie de intercambios verbales preparatorios (los turnos 1 a 8) para reparar la ruptura en la alternancia de turnos que ha supuesto la nueva presencia física. 
Pero la presencia física debe entenderse, sin embargo, no sólo como la aparición de un nuevo participante, sino como un conjunto de estímulos muy complejo con gran poder comunicativo. Incluimos en este apartado todo aquello que deriva de los sentidos y que supera a lo meramente verbal. Todos estos estímulos, desde los visuales hasta los olfativos, representan un papel fundamental en la comunicación personal, como observamos en las acotaciones que aparecen en muchas conversaciones (bostezos, carraspeos, eructos, toses, etc. $)^{49}$.

En el ejemplo (13), una nueva presencia física (¿sonora, olfativa?) estimula nuevas bromas a los jóvenes campistas de la conversación [H.38.A.1]:

(13)

A: ¿¡qué más sano que una comida entre las moscas del campoo!? (RISAS)§

B: $\S[$ RISAS)]

D: [(RISAS) y una] mier- (RISAS) y la MIERda que hay

$\mathrm{B}:{ }^{\circ}(\text { hablando de mierda/ hay alguien cagando ahi })^{\circ 50}$

A: seguro $^{51}\left(5^{\prime \prime}\right)$

[H.38.A1]

Las máquinas están programadas en función de un oyente pasivo, de un receptor "anestesiado", nosotros construimos nuestro mensaje colaborando con el otro, y utilizando todos nuestros sentidos para recibir y para emitir.

\subsection{Las risas}

Las risas son un componente habitual en las conversaciones coloquiales (véase Bravo, 1993, 96), al menos en español, y, como sucedía con los gestos, suelen acompañar a las emisiones verbales, sea solapándolas, como sucede en el ejemplo (14):

B:

[¿dónde están las papas $\downarrow$ nano? $?^{52}$ ]

C:

D: (RISAS) $\S$

[(RISAS)] ((estoy mirando arriba))

B: $\quad$ iqué cabrón! $!^{53}$

A: tú no hables $\rightarrow$ tú no hables§

[H.38.Al]

sea sirviéndolas de complemento, como comprobamos en el tercer turno del ejemplo 15:

(15)

1D1: oye y hablando un poco de todo/ hablamos ahora si os parece de la enseñanza ya que todos somos de la profesión y así (( ))

49 Véase el corpus Val.Es.Co. (2002).

50 Alusión a algunos paseantes próximos al lugar en que se desarrolla la conversación.

51 Comiendo mientras habla.

52 Entre risas.

53 Entre risas. 
2C1: ;ay no nos deprimas!/ ;con lo divertido que es esto!

3D2: ¿no? [RISAS]

[MT.97.A.1]

Sin embargo, son muy numerosas las ocasiones en las que las risas no sólo acompañan a las intervenciones habituales, sino que por sí mismas se convierten en intervenciones o turnos (3D2 y 4B1):

1D1: [el Mosca]/ el Mosca sí

2A1: ese era un cerdo

3D2: [(RISAS)]

4B1: [(RISAS)]

$5 \mathrm{Cl}$ : [(RISAS)] escupir y eructar $\uparrow$ era algo $\downarrow$ era algo innato en él [H.38.A.1]

Podría decirse que la conversación coloquial por su carácter muchas veces distendido y espontáneo está revestida de un componente lúdico que se manifiesta no sólo en las risas, sino también en los gestos, en las bromas o, como vimos en el ejemplo (7), en estrategias pragmáticas de más alcance como la ironía ${ }^{54}$ :

(17)

B: siempre tú has estao de acuerdo $\downarrow$ en ese tema/// ¿y tú Raúl $\uparrow$ opinas que los calvos son cabrones $\uparrow$ o no?

C: hombre $\downarrow$ he conocido pocos

D: (RISAS) ¿qué cabrón! y te mira ${ }^{55}$ [(RISAS)]

[H.38.A.1]

\section{Conclusiones}

Como adelantamos en la introducción, el objeto de este estudio era examinar aspectos de la comunicación y de sus componentes, apoyándonos en las informaciones aportadas por un corpus conversacional. Siguiendo los estudios del análisis del discurso, hemos definido la conversación como una sucesión de turnos, pero, añadiendo las aportaciones en este sentido del Grupo Val.Es.Co. hemos descrito este término como una unidad que recoge tanto aspectos estructurales como sociales.

La unidad turno, contemplada de esta forma, permite aportar nueva luz a la explicación de las figuras que intervienen en la comunicación. La posesión del turno caracteriza al hablante, y su falta caracteriza al oyente, pero esta descripción tiene, además, consecuencias importantes en la interpretación de los términos emisor y receptor.

Aunque estos términos tienen una gran tradición en la lingüística, en la mayor parte de los casos, su definición se ve contagiada negativamente de una interpretación inexacta de la primigenia teoría de Shannon y Weaver (1949), teoría que debe ser comprendida no como

54 Véase Padilla (en prensa 1). En esta línea son interesantes los trabajos del grupo GRIALE de la Universitat d'Alacant.

55 En ese momento C mira a A. 
incorrecta sino como producto de un objeto de estudio diferente al lenguaje humano. Hemos apuntado que a las descripciones fonocéntricas y polarizadas deben sustituir otras nuevas que reivindiquen una emisión que vaya más allá de los sonidos. Para ello, hemos aportado ejemplos conversacionales en los que el papel de hablante, necesariamente ratificado por el oyente, lo es también con mecanismos distintos de los sonoros. Hablamos en este caso de estímulos diferentes que, situados en la comunicación intencional, significan una ratificación fática del papel hablante.

La necesidad de ratificación y la conveniencia, como afirmábamos anteriormente, de considerar el concepto turno como una unidad social, nos han llevado a reivindicar un papel destacado para el oyente, pues es él, en última instancia, el que dirige la conversación y la distribución de los diferentes papeles. El oyente, como hemos comprobado en los ejemplos, es, en ocasiones, combatiente. Pero lo más importante es que, una vez diferenciadas la esfera natural y social, y una vez aceptado que la emisión es constante y heterogénea, el oyente puede ser descrito como el "director de la orquesta conversacional" y no un mero espectador o receptor.

\section{Referencias bibliográficas}

Anscombre, J.-C. y Ducrot, O. (1983): L'argumentation dans la langue. Bruxelles, Mardaga.

Baixauli, I. (1997): Lenguaje infantil y uso coloquial. La adquisición del modo pragmático. Valencia, Universitat de València (Tesis de Licenciatura).

Bajtín, M.,: (1977): Le marxisme et la philosophie du langage. Paris, Minuit.

Bravo, D. (1993): La atenuación de las divergencias mediante la risa en negociaciones españolas y suecas, Estocolmo, Universidad de Estocolmo.

Bravo, D. (1996): La risa en el regateo: Estudio sobre el estilo comunicativo de negociadores españoles y suecos. Estocolmo, Universidad de Estocolmo.

Bravo, D. (2000): "Hacia una semiótica de la identidad social: gestos en la manifestación de ideales de la personalidad socio-cultural en discursos académicos", Oralia, 3, págs. 21-51.

Bravo, D. y Briz, A. (2004): Pragmática sociocultural. Barcelona, Ariel.

Briz, A. (1996): El español coloquial: Situación y uso. Madrid, Arco-Libros.

Briz, A. (1998): El español coloquial en la conversación. Esbozo de pragmagramática. Barcelona, Ariel.

Briz, A. (2000): “Turno y alternancia de turno en la conversación”, R.A.L., págs. 23-54.

Briz, A. y Grupo Val.Es.Co. (1995): La conversación coloquial (Materiales para su estudio). Anejo XVI de la Revista Cuadernos de Filología. València, Universitat de València.

Briz, A. y Grupo Val.Es.Co. (2000): ¿Cómo se comenta un texto coloquial. Barcelona, Ariel-Practicum.

Briz, A. y Grupo Val.Es.Co. (2002) Corpus de conversaciones coloquiales. Barcelona, Ariel.

Briz, A. y Grupo Val.Es.Co (2003): "Un sistema de unidades para el estudio del lenguaje coloquial", Oralia, 6, págs. 7-61.

Briz A. y Grupo Val.Es.Co. (en prensa): "El sistema de transcripción del Grupo Val.Es.Co.".

Briz, A., Gómez Molina, J.R., Martínez Alcalde, M.J. y Grupo Val.Es.Co. (eds.) (1997): Pragmática

y gramática del español hablado. El español coloquial. Zaragoza, Pórtico.

Bülher, K. (1950): Teoria del lenguaje, Madrid, Alianza.

Calvo, J. (1994): Introducción a la pragmática del español. Madrid, Cátedra.

Ducrot, O. et al.,(1980): Les mots du discours. París, Minuit.

Ducrot, O. (1984): Le dire el le dit. Paris, Minuit. 
Escandell, M.V. (1996): Introducción a la pragmática. Barcelona, Ariel.

Gallardo, B. (1993): "La transición entre turnos conversacionales: silencios, solapamientos e interrupciones", Contextos XI, págs 189-220.

Gallardo, B. (1996): Análisis conversacional y pragmática del receptor. Valencia, Episteme.

Gallardo, B. (1998): Comentario de textos conversacionales II. Los textos. Madrid, Arco-Libros.

Geluykens, R. (1992): From Discourse Process to Grammatical Construction. Amsterdam, Benjamins.

Goffman, E. (1979): "Footing", Semiótica, 25, págs. 1-29.

Goffman, E., (1981): Forms of Talk. Philadelphia, University of Philadelphia Press.

Hernández Sacristán, C. (1999): Culturas y acción comunicativa. Introducción a la pragmática intercultural. Barcelona, Octaedro.

Hidalgo, A. (1997): Entonación coloquial. Función Demarcativa y Unidades de Habla. Valencia. Universitat de València, Anejo XXI de Cuadernos de Filología.

Hidalgo, A. y Padilla, X.A., (en prensa): "Bases para el análisis de las unidades menores de la conversación: los subactos".

Hymes, D. H. (1971): On Communicative Competence. Philadelphia, University of Philadelphia Press.

Jakobson, R. (1950): "Linguistics and poetics". En T.A. Sebeok (ed.), Style in Language, Cambridge, MIT Press.

Jakobson, R. (1967): Reading in Linguistics, II. Chicago, Toronto.

Jakobson, R., (1975): Ensayos de Lingüística General. Barcelona, Seix Barral.

Jefferson, G. (1974): "Error correction as an interactional ressource", Language in Society, 3, págs. $181-201$.

Kerbrat-Orecchioni, C., (1986): La enunciación. De la subjetividad en el lenguaje. Buenos Aires, Hachette.

Labov, W. (1983): Modelos sociolingüísticos. Madrid. Cátedra.

Leech, G. N. (1983): Principles of Pragmatics. Londres, Longman.

Levinson, S. (1989): Pragmática. Barcelona, Teide.

Moeschler, J. y Reboul, A. (1994): Dictionaire Encyclopédique de Pragmatique. París, Seuil.

Padilla García, X.A., (1996): "Miguel Delibes, estrategias argumentativas y conversacionales en el monólogo interior cotidiano Cinco horas con Mario. Diferencias entre el uso literario y el uso real", Actas del I Congrés de Lingüística General. Valencia, Universitat de València.

Padilla García, X.A., (2001): El orden de palabras en el español coloquial (tesis doctoral). Valencia, Universitat de València (Biblioteca virtual Miguel de Cervantes).

Padilla García, X.A. (2001b): "Análisis pragmático del orden de palabras en enunciados coloquiales". Cuestiones conceptuales y metodológicas de la lingüistica, Moenia, 11, págs. 45- 56.

Padilla García, X.A., (2001c): "Las unidades monológicas (intervención, acto y subacto) y el orden de palabras: una guía para su análisis en el discurso hablado", Actas del congreso de análisis del discurso, Pamplona, Universidad Pontificia de Navarra.

Padilla García, X.A., (2003): "Los papeles comunicativos y las unidades conversacionales", Actas del Congreso Alonso Zamora Vicente (Los clásicos, los contemporáneos), Alicante, Universidad de Alicante.

Padilla García, X.A., (2005): Pragmática del orden de palabras. Alicante, Publicaciones de la Universidad de Alicante.

Padilla García, X.A. (en prensa 1): "Radiografía de un fingidor: la ironía en español hablado".

Padilla García, X.A., (en prensa 2): "Ordenador, computador-ora".

Padilla, X. y Baixauli, I. (2000): "Interrelaciones en el aprendizaje de la L1 por el niño y de la L2 por el adulto". En Coperias, M. J., J. Redondo y J Sanmartín (eds.): Quaderns de Filologia, V. Estudis Lingüistics. Aprendizaje y enseñanza de una segunda lengua, València, Universitat de València, pp. $249-259$. 
Padín, C., (1997): “El operador visual en la poesía experimental”, Eye Rhymes, 3, Alberta, Universidad de Alberta.

Pla, F. et al., (2001): "Language Undertanding Using Two-level Stochastic Model with POS and Semantic Units", SCI, 11, págs. 123-150.

Portolés, J. (1998): Marcadores del discurso. Barcelona, Ariel.

Reyes, G. (1995): El abecé de la pragmática. Madrid, Arco-Libros.

Sack, H. et al. (1974): "A simplest systematics for the organization of turn-talking for conversation", Language 50, págs. 696-735.

Sacks, H, Schegloff, F. y Jefferson, G. (1974): "A simplest systematics for the organization of turntaking for conversation", en Language, 50.4, págs. 696-735.

Sacks, H. (1986): "Some considerations on story told in ordinary conversation", Poetics, 15 (127138).

Sanchis, E. et al. (2002): "Applying dialogue constraints to the understanding processs in dialogue system", Lectures Notes in Computer Science, 6, págs. 35-89.

Segarra, E. et al., (2002): "Extracting semantic information through authomatic learning techniques", International Journal of Patern Recognition and Artifitial Intelligence, 9, págs. 34-68.

Shannon, E.C. (1948): "A Mathematical Theory of Communication", The Bell System Technical Journal, 27, págs. 379-423.

Shannon, E.C. y Weaver, W. (1949): A Mathematical Theory of Communication. Urbana, University of Illinois Press.

Sperber, D. y Wilson, D. (1986): La relevancia. Madrid, Visor.

Steel, B. (1976): A Text Book, Colloquial Spanish. Madrid SGEL.

Suzuki, T. (1977): Words in context. New York, Kodansha International.

Yule, G. (1996): Pragmatics. Oxford, Oxford University Press. 